\title{
Tolerance Management in Construction: A Conceptual Framework
}

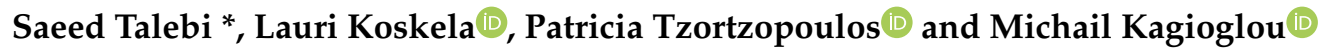 \\ Innovative Design Lab, School of Art, Design and Architecture, University of Huddersfield, Huddersfield HD1 \\ 3DH, UK; L.Koskela@hud.ac.uk (L.K.); P.Tzortzopoulos@hud.ac.uk (P.T.); M.Kagioglou@hud.ac.uk (M.K.) \\ * Correspondence: S.Talebi@hud.ac.uk
}

Received: 12 December 2019; Accepted: 27 January 2020; Published: 1 February 2020

\begin{abstract}
Defects associated with dimensional and geometric tolerance variability (tolerance problems) are often dealt with during the construction phase of projects. Despite the potentially severe consequences of those defects, tolerance management (TM) is a perennial challenge, and the construction industry lacks a systematic and practical process to provide insight into avoiding the reoccurrence of tolerance problems. The aim of this research is to present a conceptual framework to proactively reduce the reoccurrence of tolerance problems at stages preceding on site construction. The research uses an exploratory case study approach exploring TM in a civil engineering consultancy. Evidence was collated from semi-structured interviews and document analysis, and validated in a group interview. The data was analysed using thematic analysis. The study contributes to knowledge in engineering management by providing new insights into drawbacks of existing TM guidelines. It also describes a good practice application of TM by a civil engineering consultancy, and proposes a conceptual framework to improve TM, which provides a basis to develop more effective practical solutions for TM.
\end{abstract}

Keywords: dimensional tolerance management; tolerance-related defects; variations; tolerance risk; tolerance requirement; communication of tolerance information; tolerance compliance control

\section{Introduction}

Defects associated with dimensional and geometric variability are amongst the most common and recurring defects in conventional construction projects [1-4]. Those defects, called tolerance problems hereafter, may adversely impact functional requirements, e.g., water tightness [5], safety [6], serviceability, durability, constructability, the fit between components $[7,8]$, structural stability $[5,9]$, aesthetics [5,9], energy performance [10], and compliance with regulations [11]. Tolerance problems can considerably increase the cost of construction and maintenance [12], cause delays [4], and increase material wastage [13]. They influence customer satisfaction, which is integral to the success of an organisation [14], and tolerance problems are often at the centre of disputes between the consumer, contractor, supply chain, and client [15].

The management of dimensional and geometric tolerances is a perennial challenge, which arises from many interacting factors, design-related but also construction-related $[16,17]$. The most commonly known factor is that tolerances range from less than a millimetre for some factory-made components to several millimetres for many in situ components $[18,19]$, while all components must still fit together and satisfy the functional requirements of the building [18]. This, along with other factors such as poor workmanship $[3,20]$, vulnerability of contemporary buildings to building movements and the subsequent geometric changes [21], and poor tolerance compliance control [22] result in recurring tolerance problems. Several examples of tolerance problems encountered in typical construction projects (e.g., lack of fit, aesthetically unacceptable gaps, misalignments between components) have 
been presented in the literature [20,23], demonstrating the challenges in the management of dimensional and geometric variations.

Tolerance problems are traditionally dealt with at the time and place of the construction work, and the way they are modified (e.g., shimming, grouting, reaming holes, applying forces) to a great extent hinges on the labourer's experience and in situ capabilities rather than on a systematic process [20,22,24]. Despite the importance of tolerances, the construction industry currently is argued to lack a systematic and practical process for tolerance management (TM) to provide designers and practitioners proactive insight into avoiding tolerance problems [12,25-27].

This paper explores TM good practices in a civil engineering consultancy. The process of reviewing 'good practices' before attempting to improve existing practices is expected to (a) capture the accumulated learning about a process [28], (b) allow others to build upon practice and continuously improve it [29], and (c) ensure the relevance of management research to industrial practice [30-32]. In this paper, the term 'good practice', also referred to as 'one best way' [33], does not mean that there is only one path to success $[28,33,34]$, but it is defined as "a process or method that, when executed effectively, leads to enhanced project performance" [35]. As far as it is known, there is no literature analysing effective solutions used in practice for TM. Furthermore, some of the existing literature prescribes solutions that lack empirical evidence to indicate whether these have been implemented within industry and how effective they have been.

The aim of the research reported in this paper is to introduce a conceptual framework to proactively reduce the reoccurrence of tolerance problems at stages preceding on site construction. The paper is structured as follows. First, current approaches to TM and solutions to improve from the literature are discussed. The research method and a background to the case studied are given. The TM process practiced by a consultancy company is then presented. The findings and contributions to knowledge are discussed and a framework to improve TM is proposed. Finally, conclusions drawn from the research are discussed.

\section{Theoretical Background}

\subsection{Tolerances and Tolerance Management in Construction}

Materials and components cannot be exactly dimensioned and positioned as they were designed. Tolerances are defined as the accepted amount of variations of materials and components from nominal values or design specifications [18]. There are two types of tolerances: (a) Dimensional tolerances, stating the permitted amount of deviation for a specific size, e.g., floor thickness, and (b) geometric tolerances, stating the allowed amount of deviation on a specific geometric property, e.g., flatness of concrete slabs [36,37].

TM in construction is about utilising various tools and methods [4] to: (a) Minimise tolerance problems derived from dimensional and geometric variations by proactively identifying and mitigating risks related to the likelihood of an occurrence of tolerance problems, called tolerance risks hereafter [27,38], (b) ensure constructability of design, operating capability, and structural integrity [39-41], and (c) reduce lead times by avoiding tolerance problems and the associated modification process [20]. The ultimate aim of TM is to minimise costs [42], increase quality [43], and continually improve the management of tolerances [16]. These can only be achieved if more judicious decisions are made upstream in the process rather than downstream, once construction has commenced [20]. Moreover, a sustainable construction industry aims to obtain a high quality of buildings while optimising the utilisation of resources [44]. In particular, avoiding defects, such as tolerance problems, is critical to maintaining building performance $[45,46]$. Hence, TM can make a significant contribution to sustainability. 


\subsection{Current Approaches for Tolerance Management in Construction}

Current approaches for TM often start with specifying tolerances from reference documents (i.e., standards, industry guidance bulletins, and codes of practice) [4] such as [47,48], and [8]. Tolerances are specified for sources of variations, which are induced variations (i.e., manufacturing, setting-out, and erection variations), as well as inherent variations, known as building movement (i.e., geometric changes over time as a result of deflection, drying shrinkage, foundation movement, etc.) $[5,21]$. Compliance with reference documents does not necessarily mean that components will fit with each other and function properly [11]. This is because reference documents include either unreasonably tight or loose tolerances [18], and ignore accumulation of deviations [49], although there has been a call to improve reference documents [14].

Tolerance problems occur due to (a) components in connections being too small or too large, not level, misaligned, subject to excessive geometric changes [38], and (b) components are not positioned as they were designed [50]. Tolerance risks are known mainly in the connections between the structural frame and non-structural components (e.g., cladding, panelling units, pipework, lift well, stairwell) [7]. Despite the tacit knowledge of designers and construction trades about tolerance risks in such connections, those risks are often addressed in the field using ad hoc strategies and trial-and-error methods, that is, responses to tolerance risks are often reactive [24,38].

Communication of tolerance information (e.g., tolerance values, dimensional and geometric properties of components, tolerance risks) between stakeholders is of prime importance to ensure components fit and function properly [25,51]. However, such communication is often limited to a section containing a list of applicable reference documents in specifications [52], which are not necessarily relevant to the project [52,53].

Tolerance compliance control is another topic that is essential for an effective TM [54]. Tolerance compliance control presently is more about whether deviations achieved for individual components comply with tolerances specified in reference documents and specifications [55,56], and whether tolerance problems are minor and can be modified quickly (e.g., columns are out of plumbness and can be fixed by applying forces) or require major modification [20].

\subsection{Review of Proposed Solutions to Improve Tolerance Management}

The synthesis of the literature identifies that TM in construction falls into four stages, namely: Identification of tolerance requirements/risks, called 'IDENTIFICATION' hereafter $[5,15,20,27,38$, 57,58]; planning the achievement of tolerance requirements/mitigating tolerance risks, called 'PLANNING' hereafter [5,15,17,20,27,38,57-59]; communication of tolerance information, called 'COMMUNICATION' hereafter [5,15,18,20,27,38,40,57-59]; and tolerance compliance control, called 'CONTROL' hereafter $[17,20,27,40,57,60]$. For clarity, tolerance requirements concern dimensional and geometric properties of components [37].

In Table 1, the most important guidelines found in the literature to improve TM and the associated TM stage are presented. Although the focus of this research is on conventional construction, the existing guidelines for offsite construction that can be extended to conventional construction are presented as well. Additionally, the recommendations for quality management systems given in [58], which are applicable in all industries, are presented, as those recommendations could potentially be employed to improve TM in construction [61]. Quality management systems help continuously improve the quality of products, increase customer satisfaction by avoiding quality issues [14], such as tolerance problems, and subsequently, improve the performance of the industry as a whole [14]. For example, the basic principle of Total Quality Management is to reach zero defect [14]. 
Table 1. Guidelines proposed in the literature to improve tolerance management (TM) based on the identified TM stages.

\begin{tabular}{|c|c|c|c|c|c|c|c|c|c|c|c|c|c|c|c|c|}
\hline & \multirow{3}{*}{$\begin{array}{l}\text { C: Conventional Constructiono: Off-Site } \\
\text { Constructionp: Processr: Scattered } \\
\text { Recommendations }\end{array}$} & [62] & [57] & [5] & [17] & [7] & [59] & [20] & [18] & [63] & [15] & [58] & [40] & [38] & [60] & [27] \\
\hline & & C & $C$ & $\mathrm{C}$ & C & $C$ & $\mathrm{C}, \mathrm{O}$ & $\mathrm{C}, \mathrm{O}$ & $\mathrm{C}, \mathrm{O}$ & $\mathrm{C}, \mathrm{O}$ & $\mathrm{C}, \mathrm{O}$ & & 0 & $\mathrm{C}, \mathrm{O}$ & 0 & 0 \\
\hline & & $\mathbf{R}$ & $\mathbf{P}$ & $\mathbf{R}$ & $\mathbf{R}$ & $\mathbf{P}$ & $\mathbf{R}$ & $\mathbf{P}$ & $\mathbf{R}$ & $\mathbf{R}$ & $\mathbf{P}$ & $\mathbf{R}$ & $\mathbf{P}$ & $\mathbf{P}$ & $\mathbf{P}$ & $\mathbf{P}$ \\
\hline \multirow{5}{*}{ 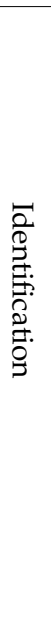 } & $\begin{array}{l}\text { Tolerance requirements should be captured } \\
\text { at early project stages. }\end{array}$ & & & & • & & & • & & & • & • & & $\bullet$ & & \\
\hline & $\begin{array}{l}\text { Class of tolerances applied to tolerance } \\
\text { requirements should be selected to ensure } \\
\text { stability and serviceability. }\end{array}$ & - & - & & & & & & & & & & & & & • \\
\hline & $\begin{array}{l}\text { Connections with a high risk of tolerance } \\
\text { problems should be identified at early } \\
\text { project stages. }\end{array}$ & & & & & $\bullet$ & & • & & & & & & • & & • \\
\hline & $\begin{array}{l}\text { Tolerance risks with negative effects on } \\
\text { dimensional and geometric accuracy of } \\
\text { components and assembles and their } \\
\text { functions should be proactively identified. }\end{array}$ & & & & & $\bullet$ & & • & & & • & • & & • & & $\bullet$ \\
\hline & $\begin{array}{l}\text { Severity of tolerance risk should be } \\
\text { estimated using qualitative, quantitative, or } \\
\text { semi-quantitative approaches. }\end{array}$ & & & & & & & & & & & $\bullet$ & & $\bullet$ & & $\bullet$ \\
\hline \multirow{3}{*}{ 矛. } & $\begin{array}{l}\text { Appropriate solutions to mitigate tolerance } \\
\text { risks, especially tolerance risks with high } \\
\text { severity, should be generated based on site } \\
\text { conditions, labour availability/skills, } \\
\text { schedule constraints, incurred costs, etc. }\end{array}$ & & - & & • & $\bullet$ & • & $\bullet$ & & & • & • & & • & & $\bullet$ \\
\hline & $\begin{array}{l}\text { Tolerance values should be collected from } \\
\text { appropriate reference documents, } \\
\text { manufacturers, designers, and contractors. }\end{array}$ & & & & & & & • & • & & $\bullet$ & & & & & \\
\hline & $\begin{array}{l}\text { Realistic tolerance values should be } \\
\text { specified based on the capability of } \\
\text { manufacturing and construction teams to } \\
\text { obtain a certain level of accuracy, } \\
\text { consequences of tolerance risks, cost of } \\
\text { manufacturing and construction. }\end{array}$ & - & & • & • & • & $\bullet$ & $\bullet$ & $\bullet$ & & & $\bullet$ & & • & & \\
\hline
\end{tabular}


Table 1. Cont.

\begin{tabular}{|c|c|c|c|c|c|c|c|c|c|c|c|c|c|c|c|c|}
\hline & \multirow{3}{*}{$\begin{array}{l}\text { C: Conventional Constructiono: Off-Site } \\
\text { Constructionp: Processr: Scattered } \\
\text { Recommendations }\end{array}$} & [62] & [57] & [5] & [17] & [7] & [59] & [20] & [18] & [63] & [15] & [58] & [40] & [38] & [60] & [27] \\
\hline & & $\mathrm{C}$ & $\mathrm{C}$ & $\mathrm{C}$ & $\mathrm{C}$ & $\mathrm{C}$ & $\mathrm{C}, \mathrm{O}$ & $\mathrm{C}, \mathrm{O}$ & $\mathrm{C}, \mathrm{O}$ & $\mathrm{C}, \mathrm{O}$ & $\mathrm{C}, \mathrm{O}$ & & $\mathrm{O}$ & $\mathrm{C}, \mathrm{O}$ & $\mathrm{O}$ & $\mathrm{O}$ \\
\hline & & $\mathbf{R}$ & $\mathbf{P}$ & $\mathbf{R}$ & $\mathbf{R}$ & $\mathbf{P}$ & $\mathbf{R}$ & $\mathbf{P}$ & $\mathbf{R}$ & $\mathbf{R}$ & $\mathbf{P}$ & $\mathbf{R}$ & $\mathbf{P}$ & $\mathbf{P}$ & $\mathbf{P}$ & $\mathbf{P}$ \\
\hline \multirow{5}{*}{ 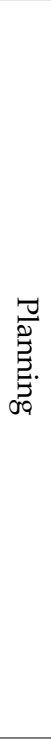 } & Tolerance analysis should be performed. & & & & & $\bullet$ & & $\bullet$ & & & $\bullet$ & $\bullet$ & $\bullet$ & & $\bullet$ & \\
\hline & $\begin{array}{l}\text { The impact of combined deviations on } \\
\text { components and sub-assemblies should be } \\
\text { evaluated (serviceability analysis). }\end{array}$ & & & & & & & $\bullet$ & & & & $\bullet$ & $\bullet$ & & $\bullet$ & \\
\hline & $\begin{array}{l}\text { The sequence of assembly process and its } \\
\text { impact on the geometric accuracy of } \\
\text { components and sub-assemblies should } \\
\text { be determined. }\end{array}$ & $\bullet$ & & & & & & $\bullet$ & & & & & & & $\bullet$ & \\
\hline & $\begin{array}{l}\text { The compatibility of the specified tolerances } \\
\text { of adjoining components in sub-assemblies } \\
\text { should be checked (tolerance coordination). }\end{array}$ & & & & & & & $\bullet$ & & & $\bullet$ & & & & & \\
\hline & $\begin{array}{l}\text { The measurement plan which includes } \\
\text { information such as the accuracy of the } \\
\text { survey process, the responsible to verify } \\
\text { deviations of components with the specified } \\
\text { tolerances, and the list of specified } \\
\text { tolerances should be prepared and } \\
\text { communicated with parties. }\end{array}$ & & $\bullet$ & & & & & & & & $\bullet$ & $\bullet$ & & & & \\
\hline 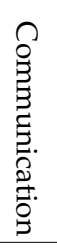 & $\begin{array}{l}\text { Tolerance information (e.g., permitted } \\
\text { deviations, used reference documents, } \\
\text { prepared measurement plan) should be } \\
\text { communicated clearly between designers } \\
\text { and construction teams via specifications } \\
\text { and drawings. }\end{array}$ & & $\bullet$ & & & $\bullet$ & $\bullet$ & $\bullet$ & $\bullet$ & & $\bullet$ & $\bullet$ & & $\bullet$ & $\bullet$ & $\bullet$ \\
\hline 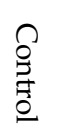 & $\begin{array}{l}\text { Deviations achieved on site should be } \\
\text { measured and their impact on the functional } \\
\text { requirements should be assessed. }\end{array}$ & & $\bullet$ & & $\bullet$ & & & $\bullet$ & & & & $\bullet$ & & $\bullet$ & $\bullet$ & $\bullet$ \\
\hline
\end{tabular}


Like TM in manufacturing [64], the improvement of TM in construction requires a process that must involve all of the TM stages $[4,15,17,20,24,25,38]$. Nevertheless, the holistic view of TM has hardly been considered in the current construction management literature. It is evident from Table 1 that only one process [20] for TM in construction could be found that covers all the identified stages (i.e., IDENTIFICATION, PLANNING, COMMUNICATION, CONTROL). In [20]'s effort to propose a process for TM, tolerance theories used in manufacturing are adopted to construction.

While the application of manufacturing tolerance theories in construction can be effective to establish a systematic TM [60], it is challenging to incorporate complex approaches from manufacturing into construction workflows [65]. This is because (a) the dominant approach for dimensional and geometric variations is to use rule of thumb or trial and error strategies [4,24]; (b) existing software, e.g., Building Information Models, do not support those approaches for most conventional construction projects [4]; and (c) a reluctance prevails in the industry to use manufacturing methodologies that are not supported by organisations developing construction standards [18,24]. In fact, knowledge transfer from manufacturing to construction must be treated with caution because the level of maturity of processes and practices is different [4], otherwise it is solely of interest to academics, without the possibility of application in practice [30].

Some of the solutions proposed in the literature are potentially costly because they require selecting more restrictive tolerances [2], changing existing measurement techniques, e.g., laser scanner [54], and using precise methods of production, e.g., robotic assembly [66]. Although such solutions can bring about improvements, dimensional and geometric variations can be still problematic due to the underlying issue of discrepancies between precise factory-made components and large site tolerances, as well as geometric effects due to building movement [21,63]. Moreover, continuous improvement, which is at the heart of Lean [67], is essential to avoid recurring problems and improve TM [68]. However, continuous improvement is not explicitly addressed in existing guidelines.

It should be noted that Table 1 only includes guidelines that do not require knowledge about complex manufacturing theories, and do not require costly production methods and measurement instruments. Furthermore, it appears that some research propose systematic processes with a set of steps e.g., [15], while the remaining are limited to scattered recommendations e.g., [18]. A number of the existing guidelines are limited to generic recommendations (e.g., improving the communication of tolerance information) e.g., [18] and do not specify precisely how those recommendations should be effectively carried out in practice. Last but not least, continuous improvement is essential to avoid recurring problems and improve TM $[14,68]$. However, continuous improvement is not explicitly addressed in those guidelines.

\section{Research Method}

This research adopts an exploratory case study approach. According to [69], such an approach can be chosen when describing, explaining, and exploring a contemporary phenomenon within a real-life context, and when the study attempts to answer "how" research questions. The exploratory case study is suitable for this research because it aims to explore TM good practices as performed by a consultancy, and answer the following 'how' questions: How to identify and communicate tolerance requirements/risks?; how to mitigate tolerance risks?; and how to verify the compliance of the achieved deviations with the specified tolerances? This exploratory research identifies linkages between theory from architecture, engineering, and construction project management and practice to inform researchers and practitioners.

The system view is adopted because this study intends to bring together principles and concepts from different domains to conduct an interdisciplinary research [70]. In view of this, the study is built on existing literature alongside empirical evidence obtained from the case study and covers concepts from three domains, namely: Architecture, engineering, and construction project management. The purpose of the literature review was to identify the underlying concepts and principles of TM; to identify the current approaches of TM in practice; to identify the relevant state-of-the-art solutions to 
improve TM; to categorise the existing solutions based on their focus; and to highlight the shortcomings of existing solutions.

\subsection{Rationale for Case Selection}

The case study project (CSP) is an engineering consultancy in the UK. Regarding the strategies for case selection, no universally accepted principles exists. The general advice is to select cases which are 'most likely' to address the research aim $[69,71]$. The case study selected was identified as a firm which is most advanced in its TM practices in the UK. This was highlighted by some of its direct competitors, who were involved in other research developed in collaboration with the authors of this paper. As such, the selection has internal validation to the context of the research, in that the actors of the context self-select good practice worthy of observation and learning.

CSP is specialised in planning, design, and control for sixty years and provides services for civil and structural engineering, infrastructure, environmental engineering, and project management. One of the major foci of CSP is the proactive identification of tolerance risks, performance of tolerance analysis, and communication of tolerance risks as part of the services offered to their clients. The company was selected as it clearly supports the purpose of the research, which was exploring a TM good practice.

\subsection{Data Collection and Analysis}

In this study, evidence was gathered from five semi-structured interviews, document analysis, and data was validated and refined through a group interview. The multiple data collection methods result in triangulation which contributes to the rigour of the research [72]. Interviews and document analysis were carried out to explore the TM process practiced by CSP, providing detailed understanding of practice [73]. According to [74], semi-structured interviews allow the interviewer to focus on important issues arising during the conversations, allow for clarification and expansion of questions and answers, and therefore, provide rich data collection. The interviewees were:

- One associate structural engineer (Interviewee A);

- three senior structural engineers (Interviewee B, Interviewee C, Interviewee D); and,

- one senior planner (Interviewee E).

Sampling is mainly associated with quantitative research; however, samples involving one or more units of observations are always applied in qualitative research [75]. A non-probability sampling (non-random sampling), based on the authors' subjective judgement, has been used in this study. Among the non-probability sampling techniques (quota, purposive, snowball, self-selected, convenience) [76], purposive sampling has been selected. This form of sampling is used when working with a very small sample, such as in case study research, and when the researcher intends to select cases that are particularly informative [76]. These two requirements apply to this case study, which selected interviewees who are aware of the TM process practiced by the CSP.

The purposive sample of this study was suggested by the CSP managing director and includes those who had developed the TM process practiced by the CSP over the last eighteen years and were directly involved in its implementation. The interviews led to the satisfactory achievement of theoretical saturation [77] because it led to a deep understanding of the practiced TM process. While five interviews may seem a small sample, the sample size in qualitative research is directly linked to the quality of data in supporting the aim of the study. In other words, the purposive sampling in this study ensured that right participants were on board and theoretical saturation, which is more important than the size of sample [78].

The interview protocol included questions exploring the process developed by CSP to manage tolerances, especially because such process had not been documented previously. Interviews were conducted and recorded face to face and they took between 60 and $110 \mathrm{~min}$. The questions in the interview protocol were: 
- How do you identify tolerance requirements/ risks?

- How do you plan to achieve tolerance requirements and mitigate tolerance risks?

- How do you communicate tolerance information?

- How do you verify the compliance of achieved deviations with the specified tolerances?

Document analysis was of vital importance in the study, as documents corroborated evidence collected from interviews and were useful in verifying information about the CSP's process for TM. The document analysis helped to increase the internal validity and trustworthiness of the study [75]. Permission was granted by CSP to access documents from two projects. The documents included Tolerance and Deflection Report and Site Visit Report. Details of the studied projects and documents reviewed in each Project are given in Table 2.

Table 2. Type of studied projects, their stage of development, and reviewed documents.

\begin{tabular}{cccc}
\hline Project & Type of Project & Development Stage & Accessed documents \\
\hline Project A & $\begin{array}{c}\text { A two-storey office } \\
\text { development }\end{array}$ & Construction & $\begin{array}{c}\text { Two Site-Visit ReportsOne Tolerance } \\
\text { and Deflections report }\end{array}$ \\
Project B & $\begin{array}{c}\text { Two sixty-storey student } \\
\text { residential buildings }\end{array}$ & Design & One Tolerance and Deflections report \\
\hline
\end{tabular}

Finally, the TM process identified was validated through a group interview. All participants of the individual interviews were invited to attend the group interview and asked whether the process has been presented adequately. In other words, the group interview was used for the refinement of the TM process description. No new steps for the TM process was found during the group interview. This shows that the identified TM process was complete. The group interview acted as a validation stage to reinforce the reliability of the collected data.

The data was analysed using thematic analysis. Thematic analysis is 'a qualitative analytic method for identifying, analysing and reporting patterns (themes) within data' [79]. Thematic analysis is a systematic, yet flexible, approach for organisation and categorisation [80] of qualitative data [81]. It describes and organises a data set in (rich) detail that results in interpretation of various aspects of the research. The thematic analysis consists of a set of procedures that are recursive and concurrent. That is, the researcher shuffles amongst the collected data, coded data, and analytical themes [75].

This research followed the steps for thematic analysis suggested by [76]. First, verbatim transcriptions from the recorded interviews were produced. Transcriptions were cross-checked with findings from the document analysis. The transcription of interviews, the refinements suggested during the group interview, and the accessed documents were reviewed [76]. In practice, this meant familiarisation of the data through reading and re-reading.

Second, concept-driven coding [78] was adopted, with initial codes developed based on the literature being used (see Table 1). The concept-driven coding intends to narrow its content search and/or coding processes for specific themes [76]. The initial codes include code 1 to code 16 in Figure 1. Third, coding, which is about assigning a code to each unit of data within a data item (i.e., a document or transcript of an interview), commenced by using initial codes. It was discovered that one further code (code 17) emerged inductively as the data was being analysed. The coded data were reviewed, and codes with similar contents were grouped into sub-themes to better describe the units of data [76]. The identified sub-themes represent the steps of the TM process in CSP. Finally, the sub-themes with similarity fell into a theme [76], which is one of the four TM stages (IDENTIFICATION, PLANNING, COMMUNICATION, CONTROL). The sub-themes and themes can be also found in Figure 1. A summary of findings is presented in the ensuing section. All quotations from interviews are presented in italics and are improved for readability. It is also indicated where the data collated from document review was used. 


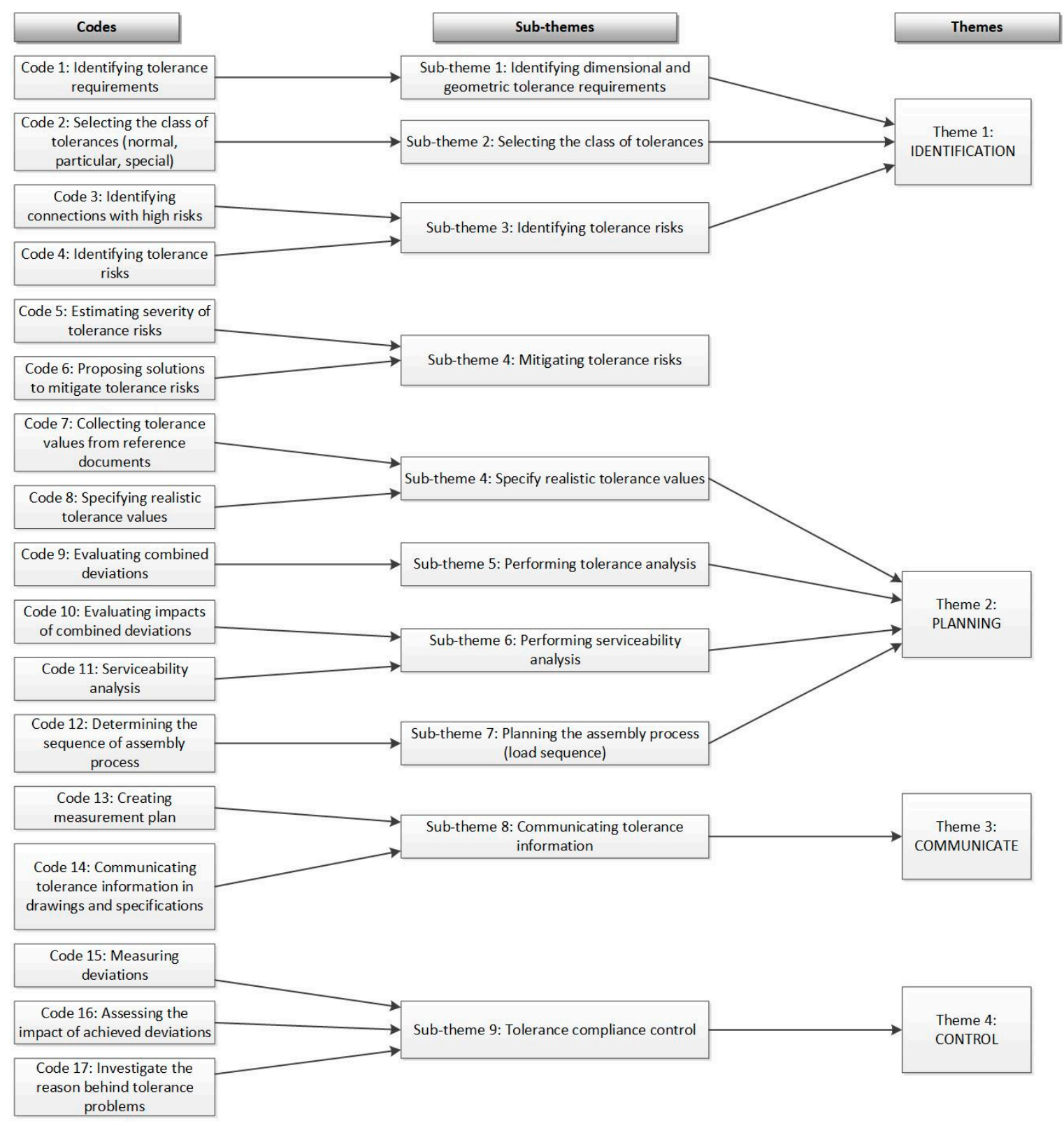

Figure 1. Codes, sub-themes, and themes used in thematic analysis.

\section{Tolerance Management Process Practiced by the Consultancy Company}

This section presents a summary of the TM process practised by CSP. An overview of the process is illustrated in Figure 2. The process has nine steps (sub-themes), and each step falls under an identified TM stage (theme). In this process, IDENTIFICATION is about ensuring dimensional and geometric tolerance values as tolerance risks are comprehensively understood; PLANNING relates to the specification of tolerance values and the functionality of components when variations of components are considered; COMMUNICATION is about using different methods and approaches to communicate tolerance information; CONTROL is about whether the achieved variations comply with the specified tolerances. According to interviewees, the objective of this process is to facilitate the coordination of tolerances among construction trades and designers in construction projects to deliver projects without any interruption in the workflow due to tolerance problems. The expert knowledge, along with the collected information from reference documents and the captured client's requirements, are inputs into this process. 


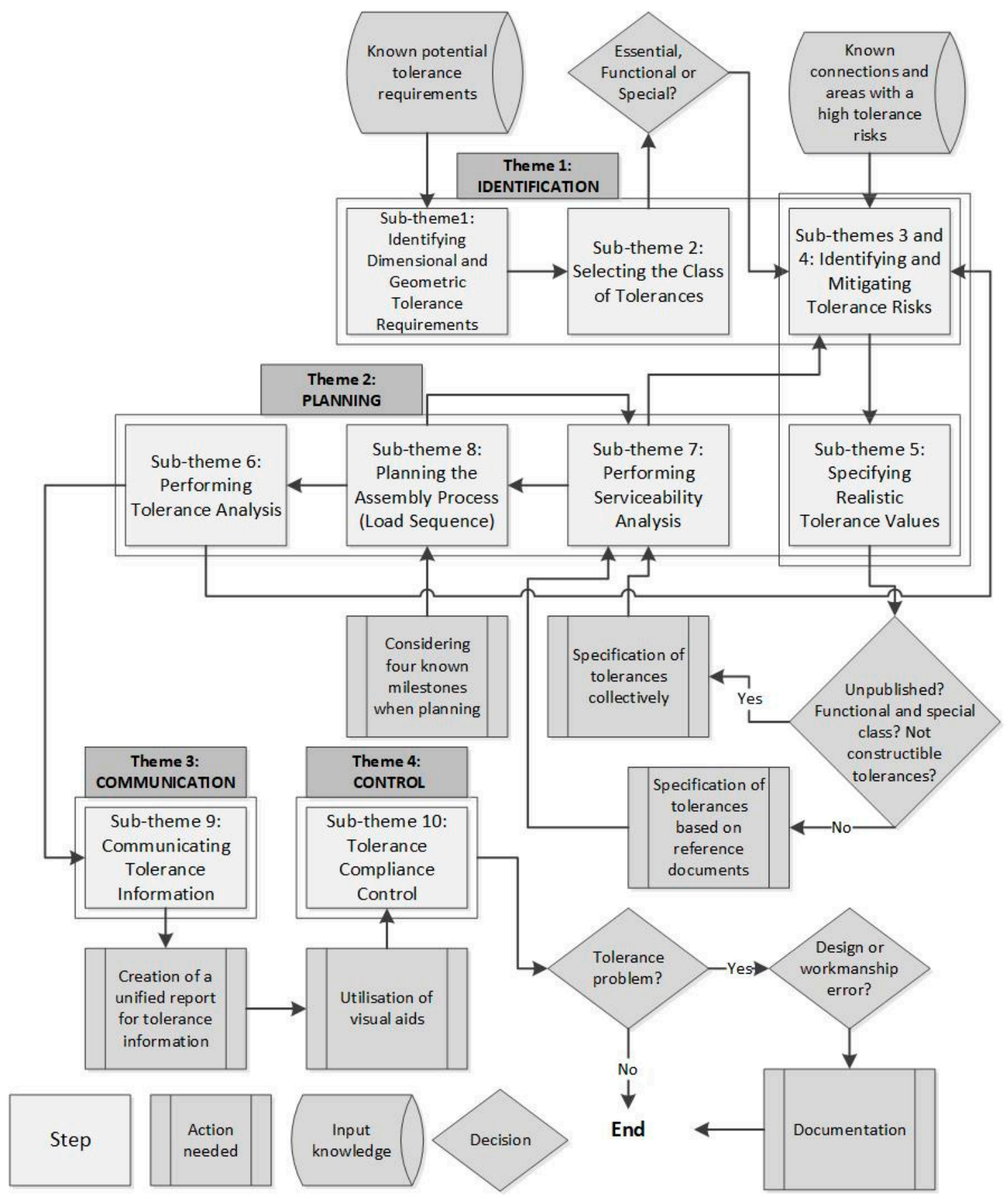

Figure 2. TM process practised by the engineering consultancy.

Identification of tolerance requirements/risks and selection of the class of tolerances fall under the IDENTIFICATION stage. The common tolerance requirements, tolerance risks, and classes of tolerances are introduced to facilitate the implementation of these steps. Tolerance values are adopted either from reference documents or based on expert knowledge, and it is ensured that the construction team can achieve those tolerance values. The serviceability analysis is performed to examine the impact of permitted geometric changes of structural members on non-structural components. The assembly sequence is planned by examining the effect of assembly sequence on the geometric accuracy of the building structure in four milestones throughout the project lifecycle. The effect of combined deviations of adjoining components on components and sub-assemblies in connections with high risks is evaluated (tolerance analysis). These steps fall under the PLANNING stage. 
Collected tolerance information is communicated to the project participants (COMMUNICATION stage) through a document called the 'Tolerance and Deflection' Report. Visual aids are used in this report to communicate the impact of variations on components, connections, and sub-assemblies to the project participants with any level of understanding of tolerances in a simple language. Finally, the compliance of deviations with the specified limits is verified and it is investigated whether occurred tolerance problems are due an error in design or construction work (CONTROL stage).

\subsection{Sub-Theme 1: Identifying Dimensional and Geometric Tolerance Requirements}

CSP attempts to "identify dimensional and geometric tolerance requirements early at the design stage and to communicate them amongst designers and construction trades" (Quotation-1-A). "Even when we are at a concept design stage, we are thinking about how that building is going to be loaded, what the general deflection criteria are, and start identifying dimensional and geometric tolerance requirements otherwise difficulties at the design and construction stages will be encountered" (Quotation-2-C). For example, "it will be problematic to develop a cladding system that is compatible with geometric changes of the building structure" (Quotation-3-C). Tolerance requirements can be captured from the client's brief, concept design, and early engagement with parties. The most common dimensional tolerance requirements, known as critical dimensions, are "floor thickness, required clearances (spaces) between components" (Quotation-4-B), and "floor to floor height in tall buildings" (Quotation-5-A). The most common geometric tolerance requirements are "straightness of edge beams, flatness of slabs" (Quotation-6-C), "parallelism of columns and stanchions" (Quotation-7-D), "plumbness of columns, position of base plates" (Quotation-8-A).

In Project A, considering the high value of office buildings, the client needs to ensure that the dimensions of the internal floor area would be as larger as possible in order to maximise the return on investment. At the same time, "the office cannot be over area because issues such as the planning permission and the extra cost will happen" (Quotation-9-B). In Project B, the envelope of the building comprises precast cladding intermixed with glazed/curtain wall elements. At the gable ends, pre-cast panels are positioned edge to edge. The initial design developed by the cladding subcontractor was to maintain a consistent $20 \mathrm{~mm}$ clearance between the panels to avoid physical clashes between them. The internal dimensions and $20 \mathrm{~mm}$ clearance are then recognised as critical dimension and subsequently, are tolerance requirements. The example of the tolerance requirement in project $\mathrm{B}$ was found in the Tolerance and Deflection Report.

\subsection{Sub-Theme 2: Selecting the Class of Tolerances}

Three classes of tolerances (i.e., the required level of accuracy) can be considered for tolerance requirements, namely essential (normal), functional, and special $[47,82,83]$. Essential tolerances can be adopted from reference documents, while functional and special tolerances are more stringent than essential tolerances [11]. Functional tolerances are applied to tolerance requirements of certain components, whereas special tolerances are applied to an entire building or structure [47,82]. The class of tolerances and their definitions were given in the Tolerance and Deflection Report of both Project A and Project B. "The class of tolerances should be selected at early design stages based on the client's brief" (Quotation-10-A). Choosing more stringent tolerances rather than normal type has cost implications and "it will be costly to apply the special class of tolerances ... It seems sensible if particular tolerances are applied where essential tolerances may not be lenient enough" (Quotation-11-E).

The importance of the dimensions of the internal floor areas of Project A has already been explained. In Project B with tall buildings, the accumulation of deviations in floor-to-floor heights may require the client to deploy additional cladding, that is, producing extra costs. "The height can be influenced by the building structure due to the deflection and workmanship errors" (Quotation-12-B). In view of this, the dimensions of the floor area and the floor-to-floor heights were recognised as critical dimensions, and the particular class of tolerances was applied only to those dimensions. 


\subsection{Sub-Themes 3 and 4: Identifying and Mitigating Tolerance Risks}

Tolerance risks are different in each type of building. In general, there are three areas in buildings with high tolerance risks (AHTRs), namely: "(a) internal components are fixed to the building structure, (b) the internal area of the building is critical and must be bound within stringent limits, (c) the building envelope is attached to the structural frame" (Quotation-13-B). "A common method to mitigate tolerance risks is to ask contractors for more stringent tolerances" (Quotation-14-D). However, "TM is not about delivering unnecessary tight tolerances" (Quotation-15-A). The best strategy to identify and deal with tolerance risks is "the early engagement with parties, especially cladding contractors, and collaboratively finding appropriate mitigation strategies" (Quotation-16-D). This is because those parties "work with their components day in/day out and have more knowledge about how to mitigate risks" (Quotation-17-D), while holding a trade-off between the satisfied tolerance requirements and the incurred costs. Examples of AHTRs, tolerance risks, reasons behind the tolerance risks, and mitigation strategies, which were found during interviews, are given in Table 3.

Table 3. Examples of the identified areas with high tolerance risks, tolerance risk, reasons behind the tolerance risks, and mitigation strategies.

\begin{tabular}{|c|c|c|c|c|}
\hline Project & AHTR & Tolerance Risk & Reason & Mitigation Strategy \\
\hline $\mathrm{A}$ & $1^{\text {st }}$ & $\begin{array}{c}\text { Aesthetically } \\
\text { unacceptable gaps } \\
\text { between internal } \\
\text { partitions and slabs }\end{array}$ & $\begin{array}{c}\text { Excessive deflection } \\
\text { (geometric changes) of slabs } \\
\text { with large spans which may } \\
\text { make internal walls } \\
\text { misaligned and not level }\end{array}$ & $\begin{array}{l}\text { Changing the } \\
\text { configuration of } \\
\text { columns }\end{array}$ \\
\hline $\mathrm{A}$ & $2^{\text {nd }}$ & $\begin{array}{l}\text { Reduced internal area } \\
\text { of offices }\end{array}$ & $\begin{array}{l}\text { Components such as walls } \\
\text { are not positioned as they } \\
\text { were designed }\end{array}$ & $\begin{array}{l}\text { Setting out very } \\
\text { accurately }\end{array}$ \\
\hline B & $3^{\text {rd }}$ & $\begin{array}{l}\text { Physical clash of } \\
\text { cladding panels due to } \\
\text { the reduced clearance }\end{array}$ & $\begin{array}{c}\text { Excessive vertical deflection } \\
\text { of the structure which may } \\
\text { make panels not level and } \\
\text { misaligned }\end{array}$ & Increasing clearance \\
\hline B & $3^{\text {rd }}$ & $\begin{array}{l}\text { Reduced floor to floor } \\
\text { height and lack of fit of } \\
\text { curtain walls }\end{array}$ & $\begin{array}{l}\text { Excessive deflection of } \\
\text { floors }\end{array}$ & $\begin{array}{l}\text { Embedding adjustable } \\
\text { connections in the } \\
\text { curtain walls }\end{array}$ \\
\hline
\end{tabular}

\subsection{Sub-Theme 5: Specifying Realistic Tolerance Values}

CSP discusses with the involved parties about what level of dimensional and geometric accuracy could be realistically achieved and whether limits in the reference documents are realistic. Under all circumstances, reference documents are referred to first, as this is a common practice in industry and is supported by regulatory frameworks (Quotation-18-D). Early engagement with parties helps to specify realistic tolerances (Quotation-19-A). According to interviewees, in three particular situations, tolerance values are found only collectively rather than referring to reference documents: (a) When standard tolerances for a component are unpublished, (b) when the particular or special classes of tolerances are applied, and (c) when the tolerance found in the reference documents is not constructible or does not guarantee that functional requirements are satisfied. The latter situation will be clarified further in the next step. The specified tolerance values are presented in the Tolerance and Deflection Report.

\subsection{Sub-Theme 6: Performing Serviceability Analysis}

"When we are designing a structural member, two factors influence the design: the strength analysis and the serviceability analysis. First, we have to consider that whether geometric changes are within an acceptable amount according to reference documents" (i.e., strength analysis) (Quotation-20-B). Afterwards, CSP performs the serviceability analysis, by which the impact of geometric changes of the structural members on non-structural components is examined. Especially, "the serviceability analysis 
for perimeter beams is important because its deflection may adversely impact the functions of the cladding system" (Quotation-21-C).

In Project A, the limit in the residual deflection of the soffit of the deck (after concreting) is given as span/130 (but not more than $30 \mathrm{~mm}$ ) [76] and accordingly, the tolerance of $28.5 \mathrm{~mm}$ for the deflection was initially allowed. After performing the serviceability analysis and considering the impact of the geometric changes of the slabs on internal components, it was decided to allow for a tighter tolerance. In Project B's building envelope, it was examined whether the panels, joints, and seals of the chosen cladding system would be damaged due to the geometric changes of the beams after they are loaded. The details of the serviceability analysis for Project A and Project B can be found in the Tolerance and Deflection Reports.

\subsection{Sub-Theme 7: Planning the Assembly Process (load sequences)}

The effect of assembly sequence (i.e., load sequence) on the geometric accuracy of the building structure is considered. There are four milestones when considering the load sequence, namely when "(a) the structure is erected, (b) the cladding is fixed to the structure, (c) finishes on floors and ceiling e.g., services, suspended ceiling and raised floors, mechanical pipes are installed, and (d) when the building is occupied" (Quotation-22-A). CSP "determines the resultant deflection of floor slabs and beams after each milestone and performs the serviceability analysis" (Quotation-23-C). The load sequence and the associated deflections for a typical concrete edge-beam are illustrated in Figure 3, which has been adopted from the Tolerance and Deflection Report of Project B.

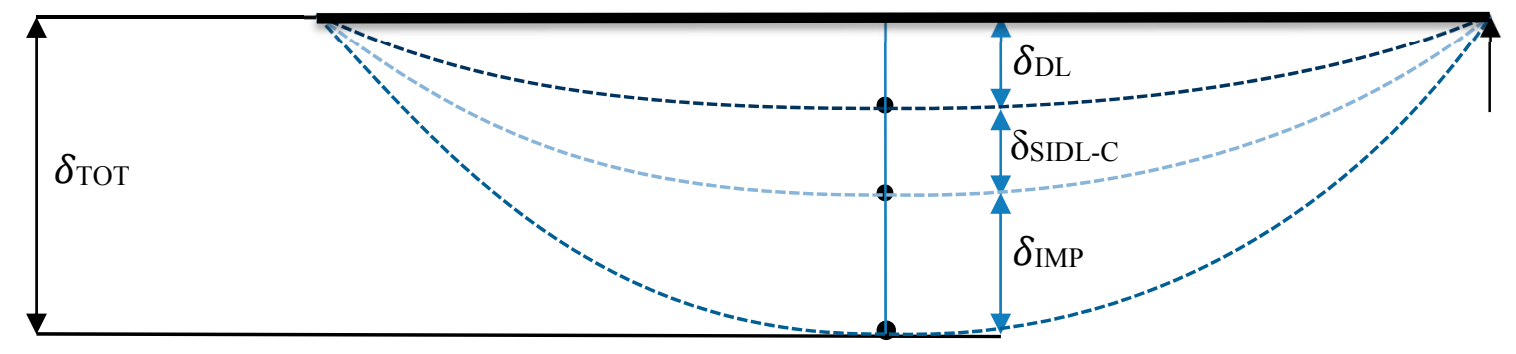
$\delta_{\mathrm{DL}}$ : Deflection due to self-weight of the structure
$\delta_{\text {SIDL-F}}$ : Deflection due to weight of the cladding and finishes
$\delta_{\text {SIDL-C: }}$ Deflection due to weight of the cladding and finishes
$\delta_{\text {IMP }}$ : Deflection due to occupancy of the building

$\delta_{\text {Tот: }}$ Total deflection of the edge beam.

Figure 3. Visual interpretation of the deflection criteria in an edge beam (adopted from Tolerance and Deflection Report of Project B).

The time point at which the cladding is installed in the construction programme is very important. This is because "deviations experienced after the cladding is installed must be incorporated within the cladding fixings" (Quotation-24-E). In other words, the cladding system should be capable of absorbing deviations due to its self-weight and any other load applied afterwards, otherwise tolerance requirements, e.g., the clearance between cladding panels, may not be satisfied. Hence, CSP coordinates with the construction planner whether the cladding is installed first or after the finishes.

In Project $B$, it was planned that the cladding system is fixed first on the edge beam and then the finishes are installed. Apparently, the cladding does not experience $\delta_{\mathrm{DL}}$, which is $10 \mathrm{~mm}$, because that has already occurred before the installation of the cladding, but it experiences $\delta_{\text {SIDL-C, }}$, which is $5 \mathrm{~mm}$, $\delta_{\text {SIDL-F}}$, which is $15 \mathrm{~mm}$, and $\delta_{\text {IMP }}$, which is $5 \mathrm{~mm}$. Given that deflections should be arithmetically added together [84], the $\delta_{\text {TOT }}$ of this edge beam is $35 \mathrm{~mm}$, but the cladding has to be capable of absorbing a deflection of $25 \mathrm{~mm}\left(\delta_{\text {SIDL-C }}+\delta_{\text {SIDL-F }}+\delta_{\text {IMP }}\right)$ only. If the assembly process was different in such a way that the finishes were installed first and then the cladding, only $\delta_{\mathrm{DL}}+\delta_{\mathrm{IMP}}=10 \mathrm{~mm}$ would need to be incorporated in the fixings of the cladding. 


\subsection{Sub-Theme 8: Performing Tolerance Analysis}

Dimensional and geometric variations of adjoining components are cumulative [36]. The evaluation of the combined variations is termed as the tolerance analysis and is performed using mathematical models [36]. The purpose of the tolerance analysis is to ensure that combined deviations of components are within the specified limits and the function of components and sub-assemblies will not be adversely influenced by the accumulation of deviations [85]. The tolerance analysis "is performed in areas where tolerance risks are identified ... but not in all of them" (Quotation-25-D).

The calculations needed for tolerance analysis are fully explained in the Tolerance and Deflection Reports of both projects. In Project B, to maintain a $20 \mathrm{~mm}$ clearance between pre-cast panels of the cladding system, the impact of the sources of deviations are analysed. Among the existing methods for tolerance analysis, the worst case and root sum square methods, suggested by [84], are used by CSP. The worst-case method (Equation (1)) and root sum square method (Equation (2)) are calculated using the Equations (1) and (2), where Dwc is the worst-case method, $D_{R S S}$ is the root sum square method, $X_{i}$ are tolerances for inherent sources of variations, $Y_{i}$ are tolerances for induced sources of variations, $\alpha=-1$ shows the clearance closes due to the accumulated deviations, and $\alpha=+1$ shows the clearance opens. The total accumulated deviation ( $\mathrm{T}_{\mathrm{TOT}}$ ) applied to one of the pre-cast panels is calculated using Equation (3).

$$
\begin{gathered}
\mathrm{T}_{\mathrm{WC}}=\sum \alpha X_{i} \\
\mathrm{~T}_{\mathrm{RSS}}=\alpha \sqrt{\sum Y_{i}^{2}} \\
\mathrm{~T}_{\mathrm{ToT}}=\mathrm{T}_{\mathrm{WC}}+\mathrm{T}_{\mathrm{RSS}}
\end{gathered}
$$

The fabrication, erection, and setting-out tolerances for each panel are found to be $3 \mathrm{~mm}, 6 \mathrm{~mm}, 5 \mathrm{~mm}$. The tolerances for horizontal movement due to vertical deflection at support and sway effects are $12.5 \mathrm{~mm}$ and $2 \mathrm{~mm}$. Tolerance analysis in the $\mathrm{x}$-direction leads to the following results: $\mathrm{T}_{\mathrm{ToT}}=-6.1 \mathrm{~mm} /$ $-22.9 \mathrm{~mm}$. Even if the clearance is not closed as a result of the accumulated deviations of one panel, it can be closed if the position deviations of both adjacent panels would be towards each other. Hence, CSP suggested to increase the clearance at the gables to accommodate possible deviations of the panels from their normal position.

\subsection{Sub-Theme 9: Communicating Tolerance Information}

The communication of tolerance information, including tolerance requirements/risks, is the most important step in TM, as it was indicated in all interviews. CSP aims to "communicate the identified tolerance requirements and risks in a simple language to other parties including architects, contractors and the supply chain who may not be fully familiar with the terms and concepts typically used" (Quotation-26-A). "Having that communication is important to make sure that everyone from designers to contractors have a full appreciation of how structural and non-structural components fit together despite of their dimensional and geometric variations" (Quotation-27-B). "If structural designers, architects and construction teams work in isolation and only account for tolerances of their own components, then tolerances of adjoining components will remain uncoordinated" (Quotation-28-D). "A lot of tolerance problems can be avoided if tolerance information is communicated at early stages before construction commences" (Quotation-29-C).

One of the main means to communicate tolerance information is via the Tolerance and Deflection Report produced by CSP. This document unifies all the tolerance information, and it is specifically prepared for communication of tolerance information. Tolerance and Deflection Report is important to ensure a common understanding has been established between parties about tolerance requirements and risks. It minimises disputes as parties can develop appropriate designs once they are aware of tolerance requirements and risks. The contents of the report are summarised in Table 4. 
Table 4. List of contents in a Tolerance and Deflection Report.

\begin{tabular}{|c|c|}
\hline Content & Description \\
\hline Tolerance-related concepts & $\begin{array}{l}\text { Tolerance-related concepts (e.g., induced and inherent deviations, class of } \\
\text { tolerances, tolerance analysis) are briefly explained. }\end{array}$ \\
\hline Permitted deviations & $\begin{array}{l}\text { A list of tolerance values for sources of variations, applied to structural } \\
\text { components, is provided. }\end{array}$ \\
\hline Class of tolerances & The selected class of tolerances for the listed tolerance requirements is delineated. \\
\hline
\end{tabular}

In the Tolerance and Deflection Report, a novel method of visualisation is used to communicate tolerance risks and their consequences during construction in a simple way. Regarding the risk identified in the cladding system of Project B, 2-D interaction of panels when subjected to vertical deflection are illustrated in Figure $4 \mathrm{a}$, and sources of variations applying to the clearance between panels are visualised in Figure $4 \mathrm{~b}$.

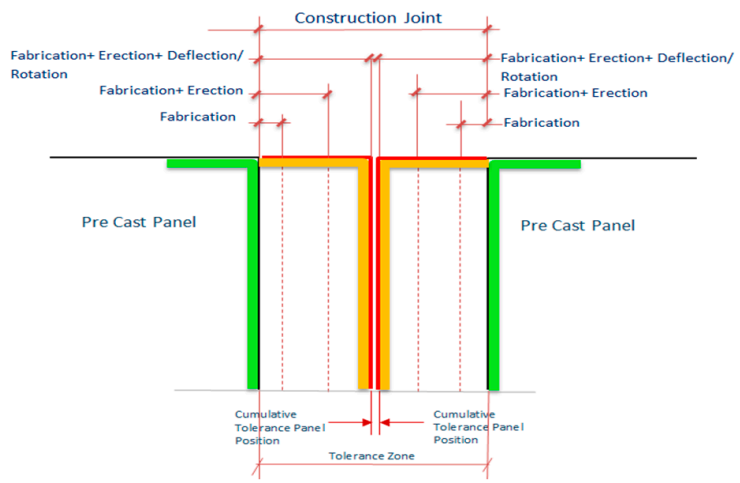

(a)

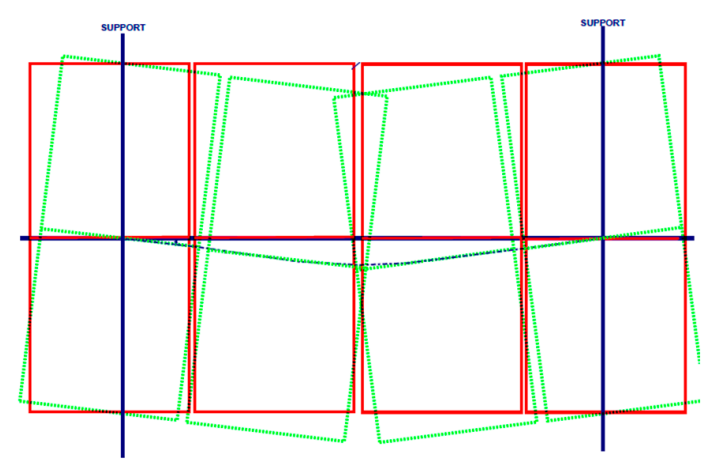

(b)

Figure 4. (a) Visualisation of the sources of deviations affecting a joint between pre-cast concrete panels; (b) arrangement of pre-cast panels before and after being subjected to sources of variations (adopted from Tolerance and Deflection Report of Project B).

\subsection{Sub-Theme 10: Tolerance Compliance Control}

CSP documents the observed tolerance problems by the quality control team and investigates whether the occurred tolerance problem was due to an error in the design or construction work. All the investigations are documented in the 'Site Visit Report'. In Project A, the cantilevered entrance canopy had deflected by up to $30 \mathrm{~mm}$ under its self-weight, whereas CSP, after the serviceability analysis, had assigned the deflection tolerance of $4.6 \mathrm{~mm}$ under the self-weight condition (Figure 5). According to the Site Visit Report of Project A, CSP ran the analysis again and demonstrated that the frame structure as designed was adequate and that the problem had been caused during the erection process of the frame.

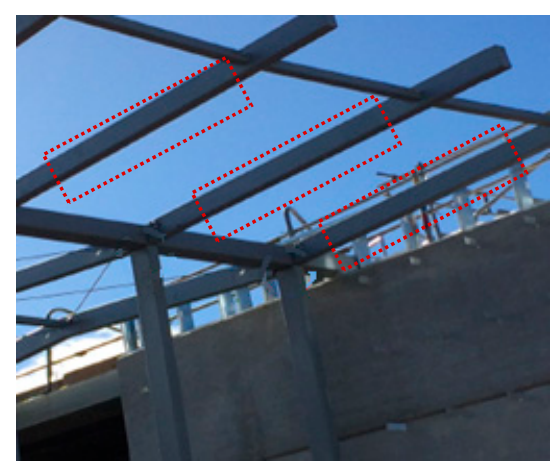

Figure 5. Deflection of the cantilevered entrance canopy in Project A (adopted from the Site Visit Report of Project A). 


\section{Discussion}

After presenting the empirical data, the first part of this section discusses the existing solution to improve TM and the explored good practice of TM by revisiting the key literature that has shaped the relevant arguments. The second part of the discussion then focuses on the proposed conceptual framework to improve TM.

\subsection{Existing Solutions And Explored Good Practice For Tolerance Management}

In this paper, the propositions to improve TM in construction $[5,15,17,18,20,27,38,40,57-60,62]$ were collated and categorised into four TM stages (IDENTIFICATION, PLANNING, COMMUNICATION, CONTROL), and are critically reviewed. Such categorisation is essential to help improve TM [86,87], however, the categorisation of TM stages in construction does not presently exist in the literature, and hence is a contribution from the research here presented. Furthermore, as argued in Section 3, the lack of a process that involves all the TM stages, application of complex manufacturing theories, and application of costly methods are the major drawbacks of the existing solutions presented in the literature, when trying to implement them in practice.

This research presented a TM good practice (Section 5). The explored TM process was considered as a good practice because its implementation does not require the application of costly methods and understanding of theories adopted from manufacturing, as opposed to most of the existing solutions in the literature $[4,11]$. In essence, such proactive process with the focus on tolerances in design avoids reactive approaches (i.e., fixing tolerance problems on site) $[13,27]$. As it can be seen from Figure 2, the process includes all of the TM stages and is applicable from project inception to project completion, unlike most of the existing solutions $[4,20,88]$.This confirms the importance of having a proactive process for TM that involves all the stages to reduce remedial actions during construction $[15,17,20,24,25,38,40]$. Moreover, a significant amount of resources during design has been invested in CSP to proactively ensure that constructed components on site are compliant with tolerance requirements. This restates the importance of focusing on tolerances at the design stage rather than reactively fixing tolerance problems on site, which can be time-consuming $[4,11,20]$, laborious, and costly $[4,20]$.

The process practiced by CSP starts from early design stages (Quotations 1-2-3) and consists of verifiable and standardised steps (see Section 4). These two qualities are in accordance with the literature $[4,17,20,24,25,38]$ on when and how TM should be implemented. However, the explored process shed additional light on how those guidelines can be used in practice (e.g., how to communicate tolerance information, how to perform the serviceability analysis for TM). More specifically, while some of the key guidelines in the literature are limited to generic recommendations e.g., [18], the process presented here can be considered as a guide allowing practitioners in industry to start dealing with tolerances systematically (Section 3). This is because a set of practical steps of an effective process for TM were clearly presented along with real examples for further demonstration. The review of such good TM practice is currently missing in the literature, while the process of reviewing good practices before attempting to improve existing practices is essential [28-32]. The explored process can be adapted by other companies and can be continuously improved to eventually develop a standard for TM rather than reinventing the wheel with each new project. The empirical data in this study is essential to deviate from theoretical knowledge without practical relevance, towards effective solutions for real-world problems [32]. While the management research in general [30], and TM in particular [24,40], have been criticised for practical irrelevance, this research contributes to support better links between theory and practice in TM.

In this process, 'identifying Dimensional and Geometric Tolerance Requirements' is the first step. The most common dimensional and geometric tolerance requirements were presented to facilitate the identification of such requirements in projects (Quotations 4-5-6-7-8). The most common dimensional tolerance requirements were found to be floor thickness, required clearances between components (Quotation 4), and floor to floor height in tall buildings (Quotation 5); the most common geometric 
tolerance requirements were found to be straightness of edge beams, flatness of slabs (Quotation 6), parallelism of columns and stanchions (Quotation 7), plumbness of columns, and position of base plates (Quotation 8). This understanding of the most common tolerance requirements is missing in the literature and is one of the findings emerged from this study.

The classes of tolerances, suggested by $[47,82,83]$ and explained in the Tolerance and Deflection Reports, are selected at early design stages. It was discussed that it is more sensible to select the particular class of tolerances where more lenient tolerances are needed (Quotation 10) because the selection of special tolerances has significant cost implications (Quotation 11). This is in in accordance with previous studies [7], however, the empirical data shed additional light on how 'particular' class of tolerances can be applied in practice (see Section 4.2).

Unlike the current reactive practice of risk management for tolerances [24,38], the presented process encourages to identify tolerance risks by early engagement of responsible parties and then reflect them in the design proactively through the 'identifying and mitigating tolerance risks' step (Quotation 16). The research clearly indicates that the best strategy to deal with tolerance risks is the early engagement with parties and collaboratively finding appropriate mitigation strategies (Quotations 14-16-17). This is because those parties are often aware of potential tolerance risks and have more knowledge about how to mitigate them (Quotation 17) while balancing the cost of satisfied tolerance requirements and the incurred costs (Section 4.3). However, previous studies e.g., $[4,15,38]$ imply that the knowledge of practitioners on tolerance risks is often disregarded by designers and project managers, and this can result in costly tolerance problems. In order to achieve the proactive identification of tolerance risks, this study reveals three areas with high tolerance risks (AHTRs) (Quotation 13) based on real examples (see Table 3). Those AHTRs are (a) the connection between internal components and the building structure, (b) the connection between the building envelope and the building structure, and (c) where the internal area of the building must be bound within stringent limits (Quotation 13). The categorisation of AHTRs is currently missing in the literature and is one of the most significant findings from this study.

Reference documents are considered first in the 'specifying realistic tolerance values' step of the explored process (Quotation 18), similar to the current practice of TM [4]. It was suggested that the specification of tolerances collectively is expected to tackle the problem with reference documents (Section 3.2), as previously found by [11,18]. However, the explored process goes beyond previous studies by revealing three situations that tolerance values should be found only collectively (Section 4.4). These situations are (a) when tolerance values for a component cannot be found in reference documents, (b) when more stringent tolerances than normal tolerances are specified, and (c) when the tolerance value specified based on the reference documents is not constructible or does not guarantee that functional requirements are satisfied (Section 4.4).

In the process practiced by CSP, the impact of geometric changes of the structural members on non-structural members is examined through the 'performing serviceability analysis' step (Quotation 20), especially for perimeter beams (Quotation 21). Four milestones, in which the serviceability should be performed, were introduced based on the findings from interviews (Quotation 22) and document analysis (Tolerance and Deflection Reports). The milestones are when (a) the structure is erected, (b) the cladding is fixed to the structure, (c) finishes on floors and ceiling are installed, and (d) the building is occupied (Quotation 22). Despite performing serviceability analysis for TM in general is suggested by $[27,57,62]$, this is the first study that has found the milestones in which serviceability analysis should be performed in the context of TM and has demonstrated performing the serviceability analysis through a real case.

The worst case method and root sum square method are used in the 'performing tolerance analysis' step because only these two methods are supported by reference documents [18]. Given tolerance analysis is perceived to be difficult and time consuming [60,85], the review of the explored good practice suggests that tolerance analysis is particularly needed in AHTRs (Quotation 25). This finding 
of this study is a contribution to knowledge, as it can facilitate TM for industry by prescribing to perform tolerance analysis only in particular areas.

Ineffective communication of tolerance information is a challenge in industry and insufficient attention has been devoted to it $[18,89]$. For that reason, it was indicated in all interviews that the communication of tolerance information in a simple language is the most important step in this process (Section 4.8). Such communication is essential to ensure tolerances of adjoining components are coordinated (Quotations 26-27) [4], adjoining components function properly [25,51], and also tolerance problems are avoided proactively (Quotations 28-29) [90]. Unlike the current practice of having specifications with scattered tolerance information [52,53], the 'Tolerance and Deflection Report', produced by CSP as part of the 'communicating tolerance information' step, is a document that unifies all the tolerance information (Quotation-30) and ensures all parties are aware of tolerance requirements and risks (see Section 4.8). This study investigated the content of the 'Tolerance and Deflection Report' and divided its content into (a) tolerance-related concepts, (b) permitted deviations, and (c) class of tolerances (Section 4.8). The proposition to have a unified document for communication of tolerance information and the content of such document contribute to the current literature.

A method is used in the 'Tolerance and Deflection Report' that uses visual aids to communicate the impact of variations on components and connections in 2-D, especially to those who may not be fully familiar with the tolerance and engineering-related concepts (Section 5). Visual aids have not yet been well deployed to improve TM [91], even though they are used in manufacturing to translate complex tolerance requirements and risks into an easily understandable language [92]. There are sources e.g., [11,20,24,93-95] that extol any improved communication of tolerance information for its ability to reduce tolerance problems, but do not offer any considerable actionable advice [90]. This study responds to the call from $[3,49,90]$ that to propose methods whereby the communication of tolerance information can be improved by revealing two novel methods (i.e., creating a document unifying tolerance information and using visual aids).

Finally, occurred tolerance problems are documented and analysed in the 'Site Visit Reports' produced by CSP during the 'performing tolerance compliance control' step to investigate whether those problems were due to an error in the design or construction work (Quotation-32). This step can be a starting point to avoid reoccurrence of tolerance problems [20] and goes beyond the current practice of tolerance compliance control in practice (Section 3.2) and existing guidelines in the literature e.g., $[20,55,56]$. However, a mechanism is still missing to enable the reuse of the knowledge gained from such analysis and reflect it in design, which is the essence of continuous improvement in TM [68].

\subsection{Proposed Conceptual Framework to Improve Tolerance Management in Construction}

In view of the system approach, the guidelines in the literature and the good practice case explored in this research are used to provide a solution to improve TM. The conceptual framework to improve TM in conventional construction projects is presented in Figure 6. The framework covers the four TM stages (themes in thematic analysis), and consists of findings from the literature and empirical study. Figure 6 also indicates whether the steps and input knowledge come from the literature and/or the empirical study.

In IDENTIFICATION, the steps were found from both the literature $[7,15,17,20,27,38,57,58,62]$ and the explored CSP. The knowledge of 'known tolerance requirements' as well as known 'connections/areas with high tolerance risks' have been found from the empirical study.

In the second part of the framework, PLANNING, the step of 'creating measurement plan' comes from the literature [57], but the remaining steps were found from both the literature $[5,7,15,17,18$, 20,38,40,57-60,62] and empirical study. Also, the knowledge of 'four milestones when performing serviceability analysis' was gained from the empirical study and was a contribution to the literature.

In COMMUNICATION, it is proposed to 'create a unified report for tolerance information' with a particular content based on the CSP good practice. Based on the TM good practice, it is also suggested to use visual aids in the report to facilitate the communication of tolerance information. 


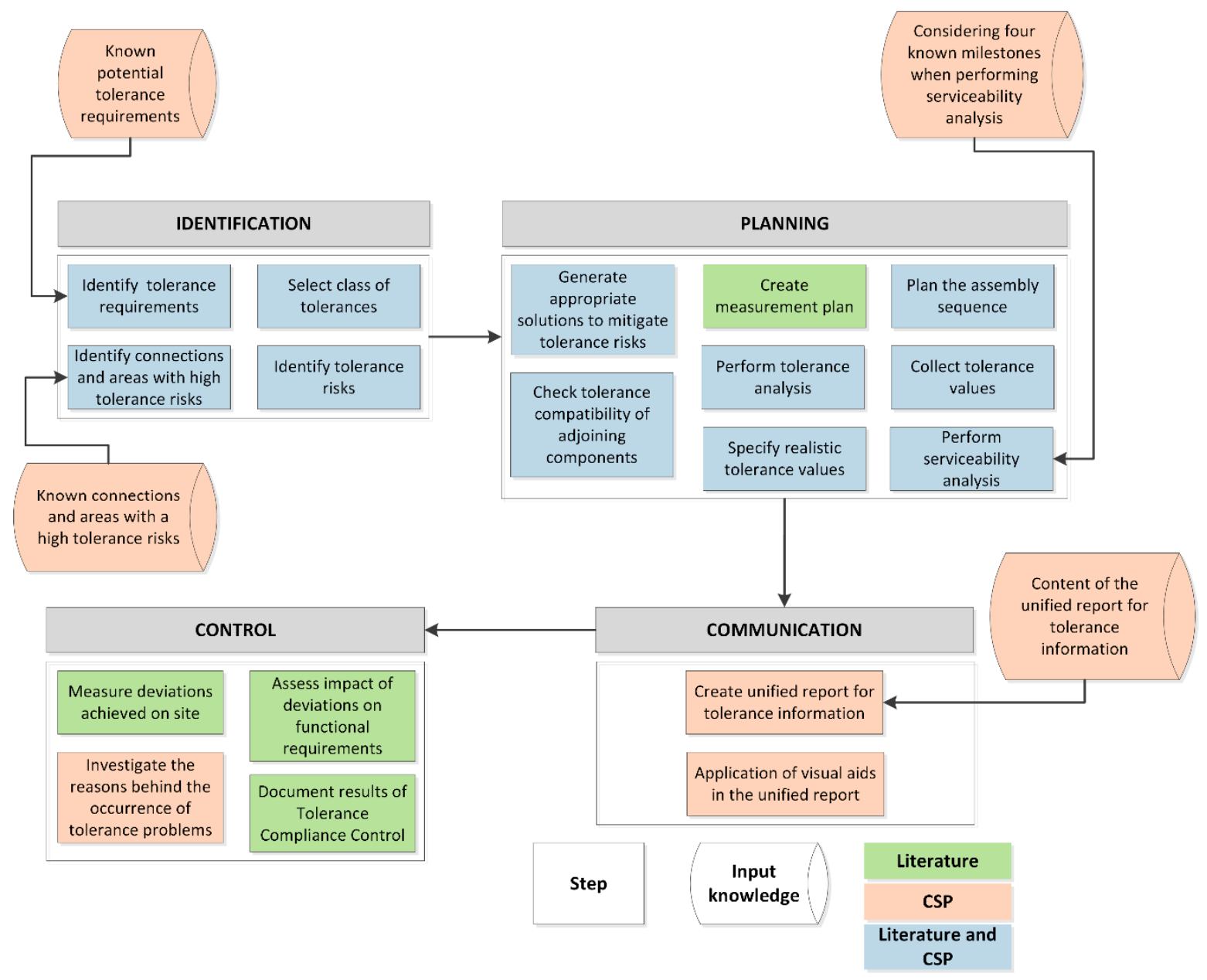

Figure 6. A holistic process to improve TM in construction.

In the fourth part, CONTROL, 'investigating the reasons behind the occurrence of tolerance problems' comes from the empirical study and the remaining steps were found from the literature $[17,20,27,38,57,58,60]$. The development of this conceptual framework is a contribution of this research because the framework integrates new concepts based on the empirical study with existing knowledge to introduce a better solution for an existing problem.

\section{Conclusions}

The aim of this research is to propose a conceptual framework as an effective practical solution to improve TM in construction. In this paper, the existing guidelines in literature are critically reviewed, and a good practice for TM in industry is explored. Empirical data and the literature were integrated to present a new framework as an effective practical solution to improve TM. Individual interviews and document analysis have been used to collate data in this research. The TM process identified through interviews and document analysis was then validated in a group interview.

The study presents key propositions to improve TM from the literature. The propositions were divided into four TM stages, namely identification of tolerance requirements/risks (IDENTIFICATION), planning the achievement of tolerance requirements/ mitigating tolerance risks (PLANNING), communication of tolerance information (COMMUNICATION), and tolerance compliance control (CONTROL). The critical analysis of those propositions revealed that a practical process, which covers all TM stages, is still missing in the literature. Moreover, the propositions require either complex manufacturing theories or costly methods. The proposed categorisation of TM stages and the presented drawbacks are currently missing in the literature and are novel contributions to theory. 
This study moves the focus from viewing one or some TM stages to adopting a more holistic view for it, and from using complex or costly methods to adopting practical steps. The TM process practised by CSP includes elements from all of the identified stages, and it has been successful to improve the CSP's performance in TM. This good practice of TM comprises a set of practical steps accompanied with examples to further demonstrate the point. It is essential to review good practices before attempting to improve existing practices while there is no literature analysing effective solutions used in practice for TM. Some of the methods in the explored process are new and do not exist in the current literature (e.g., visualisation of variations). Therefore, this research contributes to both practice and theory, as it presents a guide for practitioners and researchers seeking to improve TM.

A conceptual framework to improve TM in conventional construction projects is proposed. The framework ensures that all the TM stages are covered, and guidelines from the literature and findings from the empirical study are adopted. As far as it is known, there is no other solution in the literature as holistic as the framework proposed in this research. The framework pinpoints a basis for academics and practitioners for further improvement and its development is a contribution of this research. Proactive TM on the basis of this framework can reduce the number of defects associated with tolerances by the identification of tolerance requirements and risks early in the design stage. This should help to reduce remedial actions needed to solve tolerance problems during construction.

Future research will include implementation of the proposed conceptual framework in practice. This will help to further develop and to validate the framework thoroughly. More work is needed to align the steps in the framework to the Royal Institute of British Architectures (RIBA) plan of works [2]. Even though the RIBA Plan of Work is recognised in the UK as a design and management framework from inception to completion [96], it does not explicitly address TM.

Finally, future work may attempt to adopt and refine concepts for TM from manufacturing to construction. For example, Geometric Dimensioning and Tolerancing (GD\&T) is a symbolic language widely used to communicate both the true geometry and tolerances of components and assemblies [97]. Further research is needed to investigate the application of GD\&T in construction with the goal of developing a common language to facilitate communication of tolerance information throughout the design, construction, and inspection processes.

Author Contributions: Conceptualization, S.T., L.K., P.T. M.K.; formal analysis, S.T.; methodology, S.T., P.T., L.K., M.K.; validation S.T., L.K., supervision, L.K. and P.T., writing-original draft preparation, S.T.; writing一review and editing, S.T., P.T., L.K., M.K. All authors have read and agreed to the published version of the manuscript.

Funding: This research is funded by the Innovative Design Lab, School of Art, Design and Architecture, University of Huddersfield.

Conflicts of Interest: The authors declare no conflict of interest.

\section{References}

1. Forcada, N.; Macarulla, M.; Gangolells, M.; Casals, M. Handover defects: Comparison of construction and post-handover housing defects. Build. Res. Inf. 2016, 44, 279-288. [CrossRef]

2. Landin, A. Demands on the tolerances when industrialising the construction sector. In New Perspective in Industrialisation in Construction: A State-Of-The-Art Report; Girmscheid, G., Scheublin, F., Eds.; International Council for Research and Innovation in Building and Construction: Zurich, Switzerland, 2010; pp. 197-205.

3. Jingmond, M.; Ågren, R. Unravelling causes of defects in construction. Construct. Innovat. 2015, 15, $198-218$. [CrossRef]

4. Talebi, S. Improvement of Dimensional Tolerance Management in Construction. Ph.D. Thesis, University of Huddersfield, Huddersfield, UK, 2019. Available online: http://eprints.hud.ac.uk/id/eprint/35070/ (accessed on 30 January 2020).

5. British Standards Institution. Tolerances for Building - Part 1: Basic Principles for Evaluation and Specification; BSI: London, UK, 1988.

6. Berg, J.v.d.; Holicky, M. CIB W49 Tolerances and FIG Commission 6 Engineering Surveys; CIB publication: Amsterdam, The Netherlands, 1989; ISBN 2800525069. 
7. British Standards Institution. Guide to Accuracy in Building; BSI: London, UK, 1990.

8. American Concrete Institute. Specification for Tolerances for Concrete Construction and Materials; ACI: Farmington Hills, MI, USA, 2010.

9. CIM Steel. Design for Construction; The Steel Construction Institute: Berkshire, UK, 1997; ISBN 1859420486.

10. Fischer, M.; Khanzode, A.; Reed, D.; Ashcraft, H.W. Integrating Project Delivery; John Wiley \& Sons, Inc.: Hoboken, NJ, USA, 2017; ISBN 0470587350.

11. Davison, B.; Owens, G.W. Steel Designers' Manual, 6th ed.; Blackwell Science, Ltd.: Chennai, India, 2012; ISBN 9781405189408.

12. Milberg, C.; Tommelein, I. Role of tolerances and process capability data in product and process design integration. In Proceedings of the Construction Research Congress, Honolulu, HI, USA, 19-21 March 2003.

13. Gibb, A.G. Off-Site Fabrication: Prefabrication, Pre-Assembly and Modularisation; Whittles Publishing: Scotland, UK, 1999; ISBN 0470378360.

14. Popescu, C.-R. The Role of Total quality management in developing the concept of social Responsibility to protect public interest in associations of liberal professions. Amfiteatru Economic 2017, 19, 1091-1106.

15. American Concrete Institute. Guide for Tolerance Compatibility in Concrete Construction (ACI 117.1R-14); ACI: Farmington Hills, MI, USA, 2014.

16. Milberg, C.; Tommelein, I.D. Tolerance and constructability of soldier piles in slurry walls. J. Perform. Constr. Fac. 2009, 24, 120-127. [CrossRef]

17. Vorlíček, M.; Holický, M. Analysis of Dimensional Accuracy of Building Structures; Elsevier: Amsterdam, The Netherlands, 1989; ISBN 0444988750.

18. Ballast, D.K. Handbook of Construction Tolerances, 2nd ed.; John Wiley \& Sons, Inc.: Hoboken, NJ, USA, 2007; ISBN 9781118260227.

19. Koskela, L. An Exploration towards a Production Theory and Its Application to Construction. Ph.D. Thesis, Technical Research Centre of Finland, Espoo, Finland, 2000. Available online: http://lib.tkk.fi/Diss/2000/ isbn951385566X/ (accessed on 28 January 2020).

20. Milberg, C. Application of Tolerance Management to Civil Systems. Ph.D. Thesis, 2006. Available online: http://citeseerx.ist.psu.edu/viewdoc/download?doi=10.1.1.308.5119\&rep=rep1\&type=pdf (accessed on 30 January 2020).

21. Alexander, S. Design for Movement in Buildings, 2nd ed.; Construction Industry Research and Information Association: London, UK, 2014; ISBN 9780128104330.

22. Bradford, C.W. The Impact of the Systematic Incorporation of Tolerances on Gypsum board Installation. Ph.D. Thesis, Indiana State University, Terre Haute, IN, USA, 2017. Available online: https://search.proquest. com/openview/8235437a5504cb84e4d1f5604d3f0f81/1?cbl=18750\&diss=y\&pq-origsite=gscholar (accessed on 30 January 2020).

23. Valdes, F.J. Manufacturing Compliance Analysis for Architectural Design: A Knowledge-Aided Feature-Based Modeling Framework. Ph.D. Thesis, Georgia Tech, 2016. Available online: http://hdl.handle.net/1853/54973 (accessed on 30 January 2020).

24. Talebi, S.; Koskela, L.; Shelbourn, M.; Tzortzopoulos, P. Critical review of tolerance management in construction. In Proceedings of the 24th Annual Conference of the International Group for Lean Construction, Boston, MA, USA, 20-22 July 2016.

25. Seymour, D.; Shammas-Toma, M.; Clark, L. Limitations of the use of tolerances for communicating design requirements to site. Eng. Construct. Architect. Manag. 1997, 4, 3-22. [CrossRef]

26. McCarney, M.P. Interface Management of Offsite Bathroom Construction: Process-and People-Factors. Ph.D. Thesis, Loughborough University, Loughborough, UK, 2017. Available online: https://repository.lboro.ac.uk/ articles/Interface_management_of_offsite_bathroom_construction_process-_and_people-factors/9455024 (accessed on 30 January 2020).

27. Enshassi, M.S.; Walbridge, S.; West, J.S.; Haas, C.T. Integrated risk management framework for tolerance-based mitigation strategy decision support in modular construction projects. J. Manag. Eng. 2019, 35, 05019004. [CrossRef]

28. Liker, J.K. The Toyota Way: 14 Management Principles from the world's Greatest Manufacturer; McGraw-Hill: New York, NY, USA, 2004; ISBN 9797813770.

29. Imai, M. Gemba Kaizen: A Common Sense Approach to a Continuous Improvement Strategy, 2nd ed.; McGraw Hill: New York, NY, USA, 2012; ISBN 0071790357. 
30. Koskela, L. Why is management research irrelevant? Manag. Econ. 2017, 35, 4-23. [CrossRef]

31. Arayici, Y.; Coates, P.; Koskela, L.; Kagioglou, M.; Usher, C.; O'reilly, K. Technology adoption in the BIM implementation for lean architectural practice. Autom. Construct. 2011, 20, 189-195. [CrossRef]

32. Checkland, P. OR and the systems movement: Mappings and conflicts. J. Oper. Res. Soc. 1983, 34, 661-675. [CrossRef]

33. Kanigel, R. The One Best Way: Frederick Winslow Taylor and the Enigma of Efficiency; Penguin Group: New York, NY, USA, 2005; ISBN 9780262612067.

34. Slowinski, G.; Sagal, M.W. Good practices in open innovation. Res. Tech. Manag. 2010, 53, 38-45. [CrossRef]

35. Construction Industry Institute. CII Best Practices Guide: Improving Project Performance; CII: Austin, TX, USA, 2012.

36. Henzold, G. Geometrical Dimensioning and Tolerancing for Design, Manufacturing and Inspection: A Handbook for Geometrical Product Specification Using ISO and ASME Standards, 2nd ed.; Butterworth-Heinemann: Oxford, UK, 2006; ISBN 0750667389.

37. Creveling, C.M. Tolerance Design: A Handbook for Developing Optimal Specifications; Prentice Hall: Needham Heights, MA, USA, 1997; ISBN 0201634732.

38. Shahtaheri, Y.; Rausch, C.; West, J.; Haas, C.; Nahangi, M. Managing risk in modular construction using dimensional and geometric tolerance strategies. Autom. Construct. 2017, 83. [CrossRef]

39. Alshawi, M.; Underwood, J. Improving the constructability of design solutions through an integrated system. Eng. Construct. Architect. Manag. 1996, 3, 47-67. [CrossRef]

40. Rausch, C.; Nahangi, M.; Haas, C.; West, J. Kinematics chain based dimensional variation analysis of construction assemblies using building information models and 3D point clouds. Autom. Construct. 2017, 75, 33-44. [CrossRef]

41. Construction Industry Institute. Constructability Implementation Guide (Best Practice); University of Texas: Austin, TX, USA, 1993.

42. Landin, A.; Kämpe, P. Industrializing the construction sector through innovation-tolerance dilemma. In Proceedings of the CIB World Congress, Cape Town, South Africa, 14-17 May 2007.

43. Forsythe, P. Consumer-perceived appearance tolerances in construction quality management. Eng. Construct. Architect. Manag. 2006, 13, 307-318. [CrossRef]

44. Popescu, G.; Raluca, C.; Banța, V.C. Performance evaluation of the implementation of the 2013/34/EU directive in Romania on the basis of corporate social responsibility reports. Sustainability 2019, 11, 2531. [CrossRef]

45. Popescu, C.R.G.; Popescu, G.N. An exploratory study based on a questionnaire concerning green and sustainable finance, corporate social responsibility, and performance: Evidence from the Romanian business environment. J. Risk Financ. Manag. 2019, 12, 162. [CrossRef]

46. Popescu, C.R.G. Corporate social responsibility, corporate governance and business performance: Limits and challenges imposed by the implementation of directive 2013/34/EU in Romania. Sustainability 2019, 11, 5146. [CrossRef]

47. British Standards Institution. Execution of Steel Structures and Aluminium Structures: Technical Requirements for Steel Structures; BSI: London, UK, 2011.

48. American Institute of Steel Construction. Code of Standard Practice for Steel Buildings and Bridges; AISC: Chicago, IL, USA, 2010.

49. Price, C.; Goodier, C.I.; Fouchal, F.; Fraser, N. The Role of Standards in Offsite Construction: A Review of Existing Practice and Future Need; British Standards Institute: London, UK, 2019.

50. American Concrete Institute. Commentary on Standard Specifications for Tolerances for Concrete Construction and Materials; ACI: Farmington Hills, MI, USA, 2002.

51. Krogstie, L. Closed Loop Tolerance Engineering: An Approach for Designing Robust Products and Processes. Ph.D. Thesis, Norwegian University of Science and Technology, Trondheim, Norway, 2015. Available online: https://ntnuopen.ntnu.no/ntnu-xmlui/handle/11250/282441 (accessed on 30 January 2020).

52. Frank, G.C. Construction Quality: Do It Right or Pay the Price; Pearson Higher Education, Inc.: Upper Saddle River, NJ, USA, 2012; ISBN 0133002837.

53. Smith, R.E. Prefab Architecture: A Guide to Modular Design and Construction; John Wiley \& Sons, Inc.: Hoboken, NJ, USA, 2010; ISBN 0470275618. 
54. Talebi, S.; Koskela, L.; Tzortzopoulos, P. Tolerance compliance measurement using laser scanner. In Proceedings of the 26th Annual Conference of the International Group for Lean Construction, Chennai, India, 18-20 July 2018.

55. Bosché, F.; Guenet, E. Automating surface flatness control using terrestrial laser scanning and building information models. Autom. Construct. 2014, 44, 212-226. [CrossRef]

56. Graham, J.R.; Lindholm, E.A. Concrete tolerances: Importance and achievement in Bureau of Reclamation Construction. J. Am. Concr. Inst. 1978, 75, 49-54.

57. The Construction Industry Research and Information Association. A Suggested Design Procedure for Accuracy in Building; CIRIA: London, UK, 1983; ISBN 086017199 X.

58. International Organisation for Standardization. Quality Management Systems: Requirements (BS EN ISO 9001:2015); ISO: London, UK, 2015.

59. Prestressed Concrete Institute. PCI Design Handbook: Precast and Prestressed Concrete, 6th ed.; Martin, L.D., Perry, C.J., Eds.; PCI: Chicago, IL, USA, 2004; ISBN 9780937040232.

60. Rausch, C.; Nahangi, M.; Haas, C.; Liang, W. Monte Carlo simulation for tolerance analysis in prefabrication and offsite construction. Autom. Construct. 2019, 103, 300-314. [CrossRef]

61. Abuhav, I. ISO 9001: 2015-A Complete Guide to Quality Management Systems; CRC Press: London, UK, 2017; ISBN 131536980X.

62. A checklist on tolerances. Build. Res. Inf. 1974, 2, 144-146. [CrossRef]

63. Silva, P. Movement and tolerances. In ICE Manual of Structural Design: Buildings; Bull, J.W., Ed.; Thomas Telford: London, UK, 2012; Volume 18, pp. 267-292.

64. Curtis, M.A. Dimensional Management: A Comprehensive Introduction; Industrial Press, Inc.: New York, NY, USA, 2002; ISBN 9780831130732.

65. Kagioglou, M.; Cooper, R.; Aouad, G.; Sexton, M. Rethinking construction: The generic design and construction process protocol. Eng. Construct. Architect. Manag. 2000, 7, 141-153. [CrossRef]

66. Feng, C.; Xiao, Y.; Willette, A.; McGee, W.; Kamat, V.R. Vision guided autonomous robotic assembly and as-built scanning on unstructured construction sites. Autom. Construct. 2015, 59, 128-138. [CrossRef]

67. Womack, J.P.; Jones, D.T.; Roos, D. The Machine That Changed the World; Rawson Associates: New York, NY, USA, 1990; ISBN 0892563508.

68. Meiling, J.H.; Sandberg, M.; Johnsson, H. A study of a plan-do-check-act method used in less industrialized activities: Two cases from industrialized housebuilding. Construct. Manag. Econ. 2014, 32, 109-125. [CrossRef]

69. Yin, R.K. Case Study Research: Design and Methods, 4th ed.; SAGE Publications: Thousand Oaks, CA, USA, 2013; ISBN 978-1-4129-6099-1.

70. Arbnor, I.; Bjerke, B. Methodology for Creating Business Knowledge, 3rd ed.; SAGE Publications: London, UK, 2008; ISBN 1446202526.

71. Flyvbjerg, B. Five misunderstandings about case-study research. Qual. Inq. 2006, 12, 219-245. [CrossRef]

72. Eisenhardt, K.M. Building theories from case study research. Acad. Manag. Rev. 1989, 14, 532-550. [CrossRef]

73. Taylor, S.J.; Bogdan, R.; DeVault, M. Introduction to Qualitative Research Methods: A Guidebook and Resource; John Wiley \& Sons: Hoboken, NJ, USA, 2015; ISBN 1118767217.

74. Blumberg, B.; Cooper, D.R.; Schindler, P.S. Business Research Methods; McGraw-Hill Higher Education: London, UK, 2008; Volume 2, ISBN 9788776814212.

75. Miles, M.B.; Huberman, A.M. Qualitative data analysis: An expanded sourcebook. Serv. Ind. J. 1995, 15, 366.

76. Saunders, M.; Lewis, P.; Thornhill, A. Research Methods for Business Students, 7th ed.; Pearson Education: Harlow, UK, 2016; ISBN 9780273716860.

77. Boddy, C.R. Sample size for qualitative research. Qual. Mark. Res. Int. J. 2016, 19, 426-432. [CrossRef]

78. Brinkmann, S. Qualitative Interviewing: Understanding Qualitative Research; Oxford University Press: New York, NY, USA, 2013; ISBN 0199861390.

79. Braun, V.; Clarke, V. Using thematic analysis in psychology. Qual. Res. Psychol. 2006, 3, 77-101. [CrossRef]

80. Ghauri, P.N.; Grønhaug, K. Research Methods in Business Studies: A Practical Guide; Pearson Education: London, UK, 2005; ISBN 0273681567.

81. Bryman, A. Social Research Methods, 4th ed.; Oxford University Press: Oxford, UK, 2016; ISBN 0199689458.

82. British Standards Institution. Execution of Concrete Structures; BSI: London, UK, 2009.

83. Construct Structures Group. National structural concrete specification for building construction. In NSCS; The Concrete Centre: Surrey, UK, 2010. 
84. British Standards Institution. Tolerances for Building: Recommendations for Statistical Basis for Predicting Fit between Components Having a Normal Distribution of Sizes; BSI: London, UK, 1998.

85. Singh, P.; Jain, P.; Jain, S. Important issues in tolerance design of mechanical assemblies. Part 1: Tolerance analysis. Proc. IME B J. Eng. Manufact. 2009, 223, 1225-1247. [CrossRef]

86. Krogstie, L.; Walter, M.S.; Wartzack, S.; Martinsen, K. Towards a more comprehensive understanding of tolerance engineering research importance. Procedia CIRP 2015, 27, 29-34. [CrossRef]

87. Hong, Y.; Chang, T. A comprehensive review of tolerancing research. J. Prod. Res. Manag. 2002, 40, $2425-2459$. [CrossRef]

88. Milberg, C.T.; Tommelein, I.D. Methods for managing tolerance compatibility: Windows in cast-in-place concrete. J. Construct. Eng. Manag. 2019, 146, 04019105. [CrossRef]

89. Anderson, A.R. Construction tolerances for concrete in highway structures. J. Am. Concr. Inst. 1965, 13-18. Available online: https://www.semanticscholar.org/paper/CONSTRUCTION-TOLERANCESFOR-CONCRETE-IN-HIGHWAY-Anderson/483ce020cbb434a0c1247653fff7753557ec27dc (accessed on 24 April 2019).

90. Savoini, J.-J.; Lafhaj, Z. Considering functional dimensioning in architectural design. Front. Architect. Res. 2017, 6, 89-95. [CrossRef]

91. Da Rocha, C.; Tezel, A.; Talebi, S.; Koskela, L. Product modularity, tolerance management, and visual management: Potential synergies. In Proceedings of the 26th Annual Conference of the International Group for Lean Construction, Chennai, India, 18-20 July 2018.

92. Costadoat, R.; Mathieu, L.; Falgarone, H.; Fricero, B. Geometric specification at the beginning of the product lifecycle. In Product Life-Cycle Management: Geometric Variations; Giordano, M., Mathieu, L., Villeneuve, F., Eds.; John Wiley \& Sons, Inc.: London, UK, 2012; pp. 433-454.

93. Sacks, R.; Eastman, C.; Lee, G.; Teicholz, P. BIM Handbook: A Guide to Building Information Modeling for Owners, Designers, Engineers, Contractors, and Facility Managers; John Wiley \& Sons, Inc.: Hoboken, NJ, USA, 2018; ISBN 1119287545.

94. British Standards Institution. Design of Joints and Jointing in Building Construction: Guide; British Standards Institution: London, UK, 2013.

95. Ballast, D.K. Architect's Handbook of Construction Detailing; John Wiley \& Sons: Hoboken, NJ, USA, 2009; ISBN 0470381914.

96. Royal Institute of British Architectures. RIBA Plan of Work Overview. Available online: https://www.architecture.com/-/media/gathercontent/riba-plan-of-work/additional-documents/ ribaplanofwork2013overviewfinalpdf.pdf (accessed on 24 April 2019).

97. Krulikowski, A. Fundamentals of Geometric Dimensioning and Tolerancing, 3rd ed.; Cengage Learning: New York, NY, USA, 2012; ISBN 1285401972. 